\title{
Entre plan y mercado: algo está cambiando
}

\section{Algo está cambiando}

El Salvador, pequeña pieza del mosaico global, funciona de acuerdo con los lineamientos que imponen los centros mayores del conglomerado mundial. A inicios de los noventa, la teoría oficial e intemacional se alimentaba de la euforia generada por el libre mercado. El escenario cambia a final del siglo, cuando a la crisis financiera se agrega "la otra crisis" (J. Wolfensohn), la crisis social, la misma "deflación mundial", la "tercera vía" de.que comienzan a hablar en Europa occidental, y la afirmación de que nos hallamos en una crisis sistémica y en la fase de pos-neoliberalismo (Foro de Davos). Todos estos vaivenes de la historia y de sus ideologías parecen cohabitar ahora entre nosotros. Cuando en 1998 se redacta el primer documento, Bases para un plan de nación, sometido a consulta popular en todos los departamentos del país, y cuando unos 211 profesionales, reunidos en 19 mesas de trabajo, lo traducen en un estudio: Temas claves para un plan de nación: consulta especializada, algo está cambiando. Cuando, después de diez años de hegemonía del libre mercado, la ANEP solicita al actual gobiemo que presente un plan o programa de acción para enrumbar el estancamiento económico, algo está cambiando. Desde las bases populares, académicas y empresariales se están reclamando actos gubernamentales que nos den una visión de mediano-largo plazo, que generen estabilidad, continuidad y confianza.

Hace exactamente diez años el nuevo gobiemo-ARENA introducía el Plan de Desarrollo Económico y Social (1989-1994) con los cuatro postulados económicos extraídos de una publicación de FUSADES: Hacia una economía de mercado en El Salvador: bases para una estrategia de desarrollo económico y social (mayo, 1989). Los cuatro postulados económicos son los siguientes: (1) La propiedad privada es condición necesaria para la eficiencia de la producción. (2) El mercado libre asegura la mejor asignación de recursos. (3) La competencia garantiza el funcionamiento del mercado. (4) El Estado tiene un papel subsidiario. 
Este cuarto postulado se repetía como quinto principio filosófico: El Estado desempeña un papel subsidiario.

Los diseñadores de este cuarto postulado económico y quinto principio filosófico definían en forma clara la subsidiaridad del Estado. "El Estado tiene una esfera de acción bastante limitada en una sociedad libre, ya que su principal papel es el de velar porque se respeten las libertades y derechos de las personas, y contribuir en forma eficiente a proveer a la población más necesitada de los servicios básicos, que no se pueden proveer a sí mismos. Las funciones del Estado son dar seguridad a los ciudadanos, garantizar una administración de la justicia neutral, en la que no haya privilegios para nadie, y actuar solidariamente en la atención de los más necesitados de la población". En los años noventa interpretábamos este rumbo ideológico a la luz de dos hechos históricos: 1989, la caída del muro de Berlín; diciembre de 1991, el acuerdo de Minsk consagra la extinción de la URSS.

La historia venía a ratificar dos consignas básicas: el Estado es el problema; el mercado es la solución. Los Estados transgreden continuamente el uso social de la propiedad pública y entorpecen la creatividad de la iniciativa privada. "El establecimiento de una economía social de mercado conlleva una redefinición y limitación del Estado"'. El mercado, como regulador, engendra un crecimiento sostenido que, con un tiempo de espera, genera el "rebalse" sobre el resto de la economía. El Estado deja de ser el conductor del juego del mercado y pasaría a ser el "administrador del rebalse", actuando solidariamente en la atención de los más necesitados de la población. Este proceso requiere un tiempo de espera. El Estado no es —en teoría - un subsidiario del mercado, porque la propiedad privada, el propio mercado y la competencia no necesitan de la subsidiaridad del Estado: ellos son los reguladores y autorreguladores. El Estado adquiere dos funciones bastante complicadas: en la administración de la justicia debe ser neutral, sin privilegios para nadie. En la administración del rebalse debe mostrar una opción preferencial por los más necesitados.

No quedaba muy claro, en esos años, cómo se podía engarzar la función de solidaridad con los más necesitados y el simple papel subsidiario del Estado, a quien le correspondían "las políticas sociales sectoriales que involucran los siguientes elementos: $(a)$ sector salud y nutrición, $(b)$ sector educación, $(c)$ sector vivienda, $(d)$ sector área integral de la familia, $(e)$ sector previsión social, $(f)$ sector laboral y $(g)$ política ecológica"2. No encajaban bien todas las piezas del mosaico: estas siete funciones, aun contando con "la acción solidaria del sector privado", abarcan directamente el bienestar social de las dos terceras partes de la población, al mismo tiempo que se afirmaba que "el Estado tiene una esfera de acción bastante limitada en una sociedad libre". Esas siete funciones no son una esfera limitada y nuestra sociedad tampoco es una sociedad libre. Por otra parte, ese conjunto de funciones son netamente deficitarias, es decir, costos sin ingre- 
sos para el Estado, al mismo tiempo que se programaba la privatización de una serie de servicios públicos que, pese a ciertas deficiencias, generaban buenos ingresos al erario público. La pregunta que nos hacíamos era: con un papel subsidiario ¿el Estado podía realmente solidarizarse con la población más necesitada? ¿Quería el modelo verdaderamente engarzar la solidaridad con la subsidiaridad? — La respuesta la ha dado la historia-

Cinco años más tarde, el gobiemo de Calderón Sol da un paso más en este sendero ideológico, derruyendo el Ministerio de Planificación y Coordinación del Desarrollo Económico y Social (MIPLAN). Se dijo que ya se había cerrado el tiempo de la planificación e incluso la era de las políticas sectoriales. "En un sistema de economía de mercado no se conciben políticas sectoriales, ya que la mejor política sectorial es una política macroeconómica que fija reglas claras y estables, da libertad a los agentes económicos, facilita la creación de recursos financieros para apoyar la inversión y genera estabilidad y confianza en el cortomediano plazo". Al mismo tiempo, el gobiemo muestra la preocupación por la "magnitud de los problemas sociales", los cuales requieren para su atención "grandes cantidades de recursos, muchos años de trabajo social integrado, voluntad, dedicación y paciencia para perseverar y un cambio tanto en las estructuras de las instituciones gubernamentales del área social como un cambio en la actitud de los privados, que deben contribuir más solidariamente e involucrarse en la lucha contra la pobreza, que es un imperativo de cristiana conciencia social y una condición necesaria para la paz social"3.

Ironías de la historia. En ese mismo año 1995, la cumbre mundial sobre el desarrollo social, tenida en Copenhague, enunciaba su logotipo: "Las sociedades prósperas son las que existen en función del ser humano". Sin embargo, a nivel mundial la economía de mercado estaba gestando grandes problemas macroeconómicos: "se desarrolla la pobreza, el crecimiento con desempleo y la atomización e insolidaridad social". También es cierto que esta cumbre mundial no logró conmover la conciencia y la misericordia de los gestores de la economía de libre mercado. Los pobres ni se enteraron de que 185 jefes de Estado y otras personalidades e instituciones se habían dado cita para deliberar sobre la creciente pobreza. La cumbre abundó en "palabras huecas", porque ni siquiera se aprobó el "acuerdo 20/20": que el 20 por ciento de las ayudas que los países ricos envían a los países pobres se destine a programas sociales y, a su vez, que los países que reciben tales ayudas se comprometan a dedicar el 20 por ciento de su presupuesto a estos mismos fines. No hubo acuerdo y "los más pobres de los pobres" siguen siendo palabras huecas. Tampoco en el Salvador se dedicaron muchas líneas a esta cumbre mundial.

Cinco años más tarde, al cumplirse la década del programa-ARENA, el foro de Davos (Suiza), enero-febrero 1999, afirma que "el proceso de globalización se está desarrollando de forma irresponsable, en el sentido literal de la palabra. 
O sea, sin que nadie tenga control o responsabilidad sobre el mismo. Los problemas creados por la mundialización han desembocado en una crisis sistémica. La globalización debe adquirir un compromiso social que no tenga como contrapartida la miseria y la exclusión de millones de seres humanos en el planeta. A la pregunta: ¿quién está a cargo de la economía global? Podemos responder: NADIE. Un mundo sin controles, sin reglas, es un mundo sin seguridad".

Como en Davos las cúpulas económicas y financieras se resisten al control social del mercado, se llega a dos conclusiones sorpresivas: “Así, en último término, parece que hay que instalarse en la volatilidad financiera y en la inestabilidad económica y aprender a vivir en un mundo incierto, pero creativo y con potencial de ganancia". El potencial de ganancia justifica la inestabilidad y la inseguridad generalizada. Además, el modelo cuenta con dos salvavidas. El lado oscuro de la globalización se sitúa en el drama humano: “esta responsabilidad se transfiere a las instituciones intemacionales humanitarias, a las religiones y a la filantropía"... "Por otro lado se espera que la promesa tecnológica, con tecnologías cada vez más potentes y más baratas, contribuya decisivamente a resolver los problemas". De nuevo, el tiempo de la misericordia y del rebalse. No es de extrañar que en el foro de Davos se dijo: "comprobamos algo ya presentido por muchos; nos hallamos de nuevo en el pos-neoliberalismo"s.

\section{El Estado: ¿un chivo expiatorio?}

Con ocasión de los 100 días del nuevo gobiemo, unos con toda razón y otros sin ninguna razón han lamentado el sensible estancamiento económico, culpando al pasado y presente gobiemos por su falta de rumbo y dirección de nuestro proceso económico. Hoy todos, o casi todos, estamos de acuerdo en admitir que la estabilidad macroeconómica es frágil e inoperante y que carecemos de un proyecto económico. Sin embargo, quienes vivían en simbiosis con la ideología oficial-ARENA, quienes durante diez años entonaban su fe económica en las leyes del mercado, no tienen derecho a culpabilizar al Estado por no dirigir la economía y no presentar una planeación ad hoc. "Su Estado" hizo lo que debía hacer: no interferir, sino impulsar las fuerzas del mercado. Los defensores de la hegemonía del mercado a quien deben culpabilizar es a la misma hegemonía del mercado, a su ideología personal. Como la autocrítica es un bien tan escaso y la ideología una propiedad tan íntima, los que antes acusaban al Estado de intervencionista ahora lamentan su ineficiencia directiva. Esto es algo irónicamente contradictorio, como es contradictorio que de una ideología de mercado pueda brotar la solidaridad.

Tampoco existe mucha consistencia objetiva en quienes cierran los ojos ante la realidad presente y nos anuncian la prosperidad y el rebalse a la vuelta de la esquina, el año 2000. Esto es más grave que "el error de las computadoras". Tampoco hay sinceridad analítica en quienes pretenden explicar nuestro estancamiento intemo en función de la declinante situación de nuestros más próximos 
socios comerciales, en la deflación latinoamericana e incluso mundial. Buscando explicaciones exógenas aterrizamos en la explicación real: la mundialización neoliberal ha generado una profunda crisis financiera, económica y social. El modelo se resiste a aceptar lo que, entre otros foros y documentos, se dijo en Davos: estamos en una crisis sistémica y en la fase del pos-neoliberalismo. Este es y será nuestro debate nacional.

\section{La nueva Alianza}

Las cuatro alianzas de la Nueva Alianza generaron expectativas de un cambio de rumbo social: trabajo, seguridad, solidaridad, futuro. ¿Algo estaría cambiando? Teníamos la impresión de que el nuevo gobiemo y su novedoso equipo ejecutivo se había posesionado de la difícil herencia que recibía al cerrar el siglo. Creíamos que el nuevo presidente aprovecharía los recientes estudios económicos, realizados por profesionales nacionales, para asentar sobre ellos los lineamientos de un plan de nación. De la expectativa pasamos a la interrogante al leer las páginas introductorias del "Programa de Gobiemo: La Nueva Alianza". Sus afimaciones no encajaban en la realidad nacional. "Somos un país emprendedor insertado efectiva y oportunamente en la globalización con base en la mejora continua, en la acumulación de capital humano y en el desarrollo tecnológico. Ofrecemos oportunidades atractivas para la inversión nacional y extranjera, logrando con ello incrementar sostenidamente nuestras exportaciones, principalmente en productos agro-industriales y otros bienes y servicios de alto valor agregado. Gozamos del reconocimiento internacional por la capacidad de crear y desarrollar con calidad y competitividad nuestros productos y servicios...Tenemos una excelente calidad de vida, con más y mejores empleos, que permiten el desarrollo personal en un ambiente de prosperidad, paz y seguridad. Vemos con optimismo el futuro... El Estado tiene un rol subsidiario, es decir, todo lo que puedan realizar los privados o el mercado, debe trasladarse a éstos"... (p. 3-5)

El nuevo gobierno volvía a refugiarse en la misma fraseología y en los mismos espejismos de sus predecesores. El interrogante es si todo esto se dice en serio, con los pies puestos sobre la tierra o desde las gruesas cortinas de casa presidencial. Hasta la misma revista trimestral del Banco Central de Reserva se hubiera sonrojado al oír esta lectura de sus series estadísticas. Además, este discurso introductorio estaba siendo escrito al mismo tiempo que se publicaban: Temas claves para un plan de nación: consulta especializada. Crecimiento con participación: una estrategia de desarrollo para el siglo XXI; Estado de la nación en desarrollo humano... Desde el primer trimestre los grandes titulares de nuestros diarios ya nos venían alertando del estancamiento económico. El mismo Banco Central recortaba su proyección del crecimiento del Producto Interno Bruto. El presupuesto estatal-1999 no se aprobaba porque presentaba un agujero superior a los 3000 millones de colones, y las encuestas de opinión pública, además de despedir con una baja calificación al gobierno saliente, remachaban 
los dos grandes problemas: deterioro económico y creciente inseguridad ciudadana. Volver a decir que "el Estado tiene un papel subsidiario y que todo lo que pueden realizar el mercado y los privados debe trasladarse a éstos", era cerrar los ojos a los resultados finales de la pasada década y a los reclamos que surgían del mismo sector privado. No es de extrañar que los 100 primeros días de gobierno hayan dejado la impresión de un ausentismo de la realidad nacional. Pero, más preocupantes son los 1000 siguientes días. También el nuevo gobiemo busca la salida fácil en la contracción de nuestros más próximos socios comerciales, en el estancamiento latinoamericano e incluso en la deflación mundial, a excepción de Estados Unidos. Sería bueno que el gobiemo abriera ampliamente la puerta de la deflación mundial y lo hiciera con las mismas reflexiones que el presidente del Banco Mundial, James Wolfensohn, lo hiciera delante del G-7, del Fondo Monetario Intemacional y otros jefes de Estado, el pasado octubre de 1998, en el discurso que él titulo: "La otra crisis".

"Señor presidente, las circunstancias han cambiado mucho desde mi intervención del pasado año... Hoy, mis recuerdos son muy distintos. Imágenes sombrías, sobrecogedoras de desesperación, impotencia y miseria. De personas que tuvieron esperanzas, pero las han perdido... Hoy, mientras hablamos de la crisis financiera, en todo el mundo 1300 millones de personas subsisten con menos de un dólar al día; 3000 millones viven con menos de dos dólares al día; 1300 millones no tienen agua potable; 3000 millones carecen de servicios de saneamiento, y 2000 millones no tienen electricidad... Hemos comprobado que cuando pedimos a los gobiemos que adopten medidas rigurosas para organizar sus economías, podemos generar enormes tensiones. Quien sufre es la gente, no los gobiemos... Debemos aprender a entablar un debate en que las matemáticas no valgan más que las razones humanitarias, en que la necesidad de cambios, con frecuencia drásticos, sea compatible con la protección de los intereses de los pobres. Sólo entonces llegaremos a soluciones sostenibles... Pero, señor presidente, no podemos engañamos y hacer de cuenta que todo marcha bien. No podemos desconocer que la crisis ha revelado deficiencias y puntos vulnerables que tenemos que resolver. Tenemos que ser audaces, pero también realistas. No podemos esbozar una nueva arquitectura en dos días, ni en dos semanas. Pero tampoco podemos permitimos perder un decenio entero como ocurrió en América Latina tras su crisis de principios de los años ochenta. Es mucho lo que está en juego, demasiadas vidas humanas... Los problemas son demasiado graves y sus consecuencias demasiado importantes, para conformamos con las respuestas del pasado o con las modas o las ideologías del momento. Debemos comprometemos a actuar de consuno para conseguir resultados mejores..."6:

\section{4. "La otra alianza": la concentración económica}

Sin jugar a la dialéctica partidista (porque los partidos, en cuanto partidos, también decepcionan) resulta más certero el "Diagnóstico estructural y de co- 
yuntura", presentado por el FMNL, septiembre de 1999. En estas hojas, de circulación informal, se puntualizan algunos resultados de los "gobiernos areneros". La primera página resume su diagnóstico estructural; no todos estarán de acuerdo con todas y cada una de estas afirmaciones.

“(1) Recomposición del poder económico a partir del capital financiero y la política económica: privatizaciones; política fiscal regresiva; política de apertura económica y arancelaria sin reciprocidad; utilización de la deuda externa, las remesas y donaciones en función de los intereses de las argollas financieras. En el otro extremo, la política económica deteriora progresivamente los ingresos de las grandes mayorías de trabajadores, micros, pequeños, medianos e incluso grandes empresas.

(2) Incremento de la pobreza, del desempleo, abandono de parte del Estado de su responsabilidad en cuanto a la prestación de los servicios sociales a que tiene derecho la población según la Constitución de la República (Educación, Salud, Alimentación, empleo, vivienda y otros).

(3) Debilitamiento financiero, institucional y profesional del Estado, frente a sus responsabilidades con el desarrollo económico, social, político, con los recursos naturales, con los problemas estructurales del país, y otros.

(4) Escalada del crimen organizado y delincuencia común, operando bajo la modalidad del narcotráfico y lavado de dólares; secuestros; saqueo del Estado y otras modalidades.

(5) En resumen, el modelo económico de ARENA es especulativo:

Funciona a partir del ahorro externo:

- dedicado a comercializar las importaciones;

- dedicado a especular financieramente (dando lugar a fraudes, lavado e inversiones en el extranjero), y

- dedicado a desarticular el aparato productivo nacional: agricultura y sectores industriales.

En lo intemo:

- crea empleo superfluo a partir de un sector informal creciente;

- institucionaliza la corrupción sobre la base del no cumplimiento de la ley y una legalidad creada para ese propósito, incluyendo las leyes de privatización, las quiebras de entidades del sistema financiero;

- privilegia una economía especulativa por medio de mecanismos, tales como la desregulación del Estado y la liberalización de los diferentes mercados (bienes, servicios y financiero). La privatización ha sido uno de 
los principales mecanismos de transferencia de capital a la gran empresas: burguesía nacional y extranjera".

Entre todas las afirmaciones aquí vertidas, que responden a un sentir generalizado, merece resaltar el primer fenómeno, calificado como "recomposición del poder económico". Aquiles Montoya detalla, con abundante referencia estadística, este proceso de "La concentración de la actividad económica en El Salvador". A partir de la distribución de los ingresos del valor agregado en ramas representativas de la actividad económica (matriz insumo-producto 1990), de las declaraciones de renta y de la captación del IVA por las empresas (pequeñas, medianas y grandes) se procede al análisis de la concentración de la actividad económica. Aquiles Montoya analiza estadísticamente la concentración en los siguientes sectores: industria manufacturera; sector comercio al por mayor y al por menor; sector servicios, restaurantes y hoteles; subsector financiero y la concentración en la banca; concentración en la agroindustria: beneficiado de café e ingenios azucareros; concentración en el agro; concentración en la generación y distribución de electricidad y la concentración geográfica.

Su investigación termina con algunas "reflexiones finales", de donde extractamos unos párrafos: "La concentración del ingreso —que se explica por la concentración estadístico-estructural en la mayoría de los sectores estudiados, así como por los bajos niveles salariales, la carencia de empleo o de propiedad sobre activos que posibiliten la obtención de ingresos- se traduce o tiene como consecuencia la pobreza estructural para la mayoría de la población. Este tipo de pobreza no tiene un carácter coyuntural y pasajero sino permanente, y su causa es tan profunda que subsiste, incluso, pese a la enorme cantidad de dólares provenientes de las remesas y que mayoritariamente se convierten en consumo. Ahora bien, es innegable que los niveles de pobreza, absoluta y relativa, serían mayores si no se contara con los pobre-dólares...

... La concentración en el ingreso no sólo es causa directa de la pobreza, sino que adicionalmente limita, bloquea o entorpece cualquier intento serio y racional para combatirla dentro de los marcos tradicionales. Ya que cuando existe concentración en el ingreso, existen mercados reducidos y raquíticos que frenan cualquier esfuerzo de crecimiento de la economía que pudiera generar empleo e ingresos en proporciones suficientes como para abatir la pobreza. Afectar la distribución del ingreso es una tarea clave, necesaria y urgente para cualquier gobiemo que se preocupe por la viabilidad de nuestra sociedad, ya que para estimular el desarrollo del sector real de nuestra economía es condición indispensable la mejora de la distribución del ingreso, que posibilitaría un crecimiento endógeno y autosostenido. De no aprovecharse el limitado tiempo que, como última oportunidad nos están ofreciendo las remesas, ciertamente las posibilidades de alcanzar un desarrollo humano sostenible serán cada vez más remotas para El Salvador". 
Aquiles Montoya termina su artículo proponiendo tres clases de medidas. Por la vía de mercado y de los precios, primero, "mejorar los salarios reales de los trabajadores del campo y de la ciudad, ya que es una vergüenza que el salario medio tienda a igualarse con el salario mínimo; segundo, mejorar los términos de intercambio de los productores agrícolas tradicionales; posibilitar a los productores agrícolas tradicionales la conservación de sus productos de manera que no vendan en cosecha, cuando los precios están deprimidos y, finalmente, crear un banco rural inmobiliario orientado a dos líneas fundamentales: crédito de avío y crédito a largo plazo para la compra de tierra e inversión en la misma".

Las medidas de corte gubernamental tienen que ver con: "primero, la asignación de mayores recursos a educación, pero la educación debe ser formal y técnica desde la primaria, de tal manera que el joven pueda obtener beneficios inmediatos del saber práctico obtenido; segundo, política fiscal seria, agresiva, combativa y correctiva. El mercado contribuye a que se concentre el ingreso, lo cual es una imperfección de toda economía mercantil capitalista; por tanto, el gobiemo debe corregir tal distorsión y al hacerlo buscará captar mayores recursos de quienes tienen mayores ingresos, perseguir a los evasores como auténticos ladrones que son y usar los recursos obtenidos de manera responsable, esto es, invirtiendo en actividades que tengan como resultado la disminución de la desigual distribución del ingreso, por ejemplo en programas de mejora de la productividad, en programas de construcción de vivienda bajo el sistema de ayuda mutua, en salud descentralizada etc. Y, finalmente, vía organismos no gubermamentales calificados como honestos y capaces, de manera que acompañen de manera eficiente procesos de desarrollo socioeconómico en comunidades organizadas, ya sean urbanas o rurales. Los recursos deben ser proporcionados por empresas que obtengan ganancias multimillonarias, los cuales serían deducibles de impuestos y, además, serían el mejor seguro para continuar lucrando sus riesgos"'

Este análisis de A. Montoya nos viene a recordar que la concentración económica es el resultado terminal de una economía de libre mercado. Esto es lo que está sucediendo a nivel mundial. Tampoco esta es la primera vez que esto sucede en El Salvador. En 1984, entrados en la guerra prolongada, nuestro departamento de economía realizó varios análisis que confluían en una "Visión global sobre la concentración económica en El Salvador"'. Quince años más tarde, la misma economía de mercado reencarna similar proceso de concentración, aunque haya algunos cambios en la lista de los beneficiados. Tal vez el mayor problema no sean los cambios en la lista de beneficiados y perdedores; el interrogante mayor es si la nueva concentración económica es más quebradiza, por cuanto se asienta sobre una economía más desarticulada. 


\section{5. ¿Una concentración quebradiza?}

Junto con los pronósticos, algo maquillados, del Banco Central de Reserva, se están multiplicando los análisis de coyuntura económica; los sectores empresariales prestan gran atención a los análisis de FUSADES, más apegados a la declinante realidad. Nuestro departamento de economía-UCA está presentando su tercer análisis de coyuntura económica, correspondiente al primer semestre de 1999. Lo que tienen de positivo todo este conjunto de estudios es que muestran que la canonizada estabilidad macroeconómica es inoperante y, por lo tanto, no es estabilidad. Se trata de una pequeña, pero importante, revolución de la teoría económica sobre el crecimiento. Nuestra economía real y casera es la siguiente: el crecimiento económico es débil, el subempleo muy elevado, los salarios reales estancados durante una década, los precios bajos por la reducción de la triple demanda de consumo, inversión y exportaciones; la tasas reales de interés son elevadas y elevada también la mora en el sistema bancario; el déficit fiscal sobrepasa los límites tolerables, mientras la carga fiscal se mantiene baja, y el déficit sostenido de la balanza comercial pone al descubierto las deficiencias del aparato productivo".

Este resumen introductorio muestra suficientemente que no hay una esfera de la economía sana y sostenible, por el hecho de que el deterioro de la demanda deficiente transmite su impotencia al resto de las áreas productivas y monetarias, incluido el erario público. Algunas cifras sorpresivas muestran la seriedad del problema; al ritmo del actual crecimiento (1996-1999) harían falta 74 años para duplicar la producción por habitante, y siete siglos para duplicar el consumo privado per-cápita. Si los salarios reales mínimos y medios permanecen estancados durante una década y el subempleo es creciente y de calidad inferior, se explica la parálisis del consumo privado per-cápita.

Igualmente serio es que nuestra inflación se convierta en deflación. En nuestro análisis de coyuntura económica se cita la revista The Economics (febrero, 1999), donde se afima que el mundo está entrando en una fase de "deflación global", por primera vez, desde los años treinta, "La deflación puede ser negativa o positiva, dependiendo de si esto lleva a una depresión, o si en realidad es el resultado de aumentos en la productividad" (pp. 19-21). En nuestro caso no hay espacio para una deflación positiva, dado el rezago tecnológico que merma nuestra capacidad competitiva. Nos enfrentamos a una deflación negativa derivada de la caída acumulada del consumo, inversión y exportaciones. "La deflación también puede ser peligrosa porque si continúa, la carga de la deuda de las empresas se hace más pesada, corriendo mayores riesgos de mora, que se podría trasladar a los bancos". Esta ha sido la secuencia de 1999, hasta el punto de inventar un posible flotador: el salvataje de las empresas y de los bancos. Parecería que los pobres y excluidos del modelo le devuelven el boomerang al resto de la economía: nosotros no podemos comprar y ustedes no pueden vender. 
Tampoco el Estado se libra de esta resaca económica y su principal tarea es rebuscar quien puede ser su "subsidiario". En estos días de octubre se inician los debates sobre el presupuesto del 2000. Los diarios nos han presentado la distribución del 6.7 por ciento del incremento entre las partidas tradicionales, incluidas las deudas interna y externa. El interrogante está en el reverso de la página; pendientes aún de cómo cerrar el déficit de 1999, superior a los 3000 millones de colones, se repite la misma historia: "Por tercer año consecutivo fisco presenta presupuesto desfinanciado" (La Prensa Gráfica, $1^{\circ}$ de octubre de 1999; p. 60). Los diarios del 12 de octubre comentan la maratónica exposición del presupuesto en la Asamblea Legislativa. A los déficit acumulados se agrega una luz roja: "Las pensiones, una amenaza para el Fisco". La proyección de la deuda total respecto al PIB pasará de un 26,7 por ciento en el año 2000 a 28,93 por ciento en el 2004 . El Estado deberá ir asignando al fondo de pensiones ISSS-INPEP las siguientes cantidades, expresadas en millones de colones: 452 en el 2000; 1000 en el 2001; 1600 en el 2002; 2303 en el 2003 y 3354 en el 2004. En total, 8770 millones. El Ministro de Hacienda afirma que los tributos, especialmente en el año 2005, serán insuficientes para financiar los aportes del fondo. ¿Más impuestos, más endeudamiento o una nueva ley de funciones? ¿La eutanasia para los jubilados? El actual gobiemo, al sentirse pobre, se acordó de los pobres y les pidió que tuvieran a bien cancelar el IVA de sus alimentos básicos y medicinas. Esperamos que sean otras las fuentes que engrosen los ingresos tributarios y que eleven la carga fiscal por encima del 10 por ciento del PIB. Del tema fiscal y del presupuesto-2000 oiremos bastante en los próximos tres meses, y ojalá no en los cinco primeros meses del nuevo milenio.

Desde inicios de 1999, el Banco Central proyectaba un déficit de la balanza comercial equivalente a los 1727 millones de dólares. El déficit real se va acercando al pronóstico y, en última instancia, las remesas de emigrantes vuelven a ser el "salvataje" de nuestra economía. Ironías de nuestra historia económica: las remesas de los pobres lejanos están sacando a flote una economía poco solidaria con los pobres cercanos. En todo este escenario económico, como afirma nuestro análisis de coyuntura, "la política monetaria realmente se ha excedido en su celo por combatir la inflación, principalmente cuando el país está atravesando momentos difíciles... Así, por lograr la estabilidad monetaria, se puede poner en peligro la estabilidad financiera". Estos son los efectos de las elevadas tasas de interés reales, que pueden explicarse pero no justificarse.

Una lectura de este análisis de coyuntura económica-1999 muestra en forma bastante clara las débiles bases de nuestra estructura productiva, sobre la que se asienta la misma concentración económica. Hay otras razones para hablar de su estructura quebradiza. En 1997 nos preguntábamos: “ $¿ E s$ el crecimiento la locomotora de nuestra economía?"'1". Llegamos a la conclusión de que se trataba de un crecimiento ambiguo y negativo. 
Para comenzar, a partir de 1995 el Banco Central ha dejado de calcular el Producto Nacional NETO, es decir, lo que el país puede producir sin empobrecerse. Más que los problemas de cálculo, realizado por otras instituciones, lo que verosímilmente asustaba era el elevado monto del deterioro ecológico, equivalente al 5 por ciento de PIB (FUSADES, 1997). En el ciclo recesivo 19961999... estábamos cosiendo y descosiendo, porque el crecimiento sectorial contable devaluaba en mayor proporción la capacidad productiva del país. La contabilidad puede esconder cifras, pero no puede cambiar la realidad. Ahora trabajamos con un Producto y una Renta Brutos, donde al primero no se le resta el deterioro ambiental y a la segunda se le agregan las crecientes remesas familiares, que son externas y pudieran contabilizarse en la cuenta de capital. Es claro que este deterioro ambiental es una de las causales del estancamiento económico.

En segundo lugar, y de esto muchos somos los culpables, se da un rezago y una aversión a la investigación e inversión tecnológica, que nada tiene que ver con la proliferación de los celulares. Ciertamente, las décadas de los setenta y ochenta no fueron las más propicias para un proceso de reconversión industrial, en sentido amplio, y el sector privado, por su parte, buscaba más bien el apoyo del compadrazgo gubernamental, las subvenciones-exenciones, el crédito barato y el recurso a la publicidad (S. Osvaldo Bran). Cuando, en 1992, se crea CONACYT, el "huracán de la globalización" nos halla desprevenidos, como nos sucede con los otros huracanes. El creciente déficit de la balanza comercial es un repetido PAES de nuestro rezago y aversión tecnológica. La inversión en programas terminales de informática no llega a la raíz del problema, que se ubica en el mismo nacimiento del sector primario-agropecuario.

Como ya lo habían señalado varios institutos de investigación, en el citado artículo, haciendo referencia a los análisis comparativos de las matrices 19781990, resaltábamos el debilitante deslizamiento de la "terciarización económica". No vale decir que este mismo proceso se viene dando desde hace décadas en las economías desarrolladas, porque las razones son muy distintas e incluso opuestas. En esas economías, el sector primario y dentro de él el sector agropecuario se caracterizan por una superprodución derivada de la tecnología y de los avances biogenéticos. Igualmente, su sector terciario se está industrializando con la revolución informática. En nuestro caso, el sector primario-extracción es cuasi inexistente, y el sector agropecuario todavía desconoce la civilización del arado; nos enfrentamos a serios problemas de seguridad alimentaria.

Sumando el rezago tecnológico al deterioro ambiental, se han ido agotando los "nichos productivos" en amplias ramas del sector manufacturero-industrial. Como indica Frank Hinkelammert, ante la agresividad de la competitividad extema y sin apoyo y protección nacional, el capital no se destina a la inversión productiva, sino a la inversión especulativa y/o a la cacería de las privatizaciones. Mientras tanto se engrosa el sector informal a causa de un crecimiento con 
subempleo. Este proceso de terciarizac ión está presentando serios efectos regresivos al irse cerrando los nichos-productivos en dos amplios sectores, generadores de empleo, valor agregado y divisas de exportación.

Lenta pero realmente estamos dando un giro desde una economía centrada en el trabajo y la producción hacia una economía fundamentada en la especulación y en las importaciones. De acuerdo con la teoría de las ventajas competitivas, todos ganarían en este modelo de libre intercambio, porque comprar barato no es la peor forma de comprar. Sin embargo, si el cúmulo de ingresos perdidos por el cierre de empleos y producción supera el monto de compras realizadas, las ventajas competitivas se convierten en pérdidas negativas. Así se profundiza el crecimiento con subempleo y desigualdad, mientras que en el mediano plazo disminuye nuestra capacidad para comprar. La deflación negativa de 1999 es una llamada de alerta sobre la agravación de nuestra demanda deficiente nacional; lo siente el sector consumidor, el sector empresarial y, finalmente, el sector bancario.

Al mismo tiempo que unos supermercados absorben a otros supermercados, se anuncia la instalación de nuevos hiper-mercados. Estos super-hipermercados, que harán quebrar a pequeños y medianos comercios y empresas, ¿encontrarán en el mediano plazo una demanda sostenible? Y las tarjetas de crédito, ¿seguirán teniendo crédito?; ¿por cuánto tiempo se podrá sostener el consumo a crédito? Todo esto pone en duda que "nuestra oferta haya creado su propia demanda". En este sentido decimos que la concentración económica es bastante quebradiza.

\section{A la búsqueda de sectores dinamizantes}

Con fecha 6 de octubre de 1999, La Prensa Gráifica, en la sección de Economía, recoge las preocupaciones de los representantes de ASI-ANEP, a partir del monitoreo mensual de la actividad económica preparado por FUSADES. Los titulares vienen a confirmar lo expresado en párrafos anteriores. "Actividad económica sigue cayendo en agosto. Actualmente todos los sectores están entrampados y la ANEP anda tras la búsqueda de su reactivación. ANEP pide proteger industria local"; en concreto se pide detener la invasión de productos que llegan de China a precios bajísimos. Una semana antes, 28 de septiembre, en la misma sección de Economía, cinco conocidos analistas afirman: "Economía necesita nuevo impulso. Se requieren políticas que desentrampen lento crecimiento. Hay un problema de demanda y de seguridad, que si no se enfrenta, difícilmente se resolverá el tema del crecimiento fiscal" (p. 24-25). Quince días más tarde, 13 de octubre, la encuesta empresarial de FUSADES "señala que el empleo en las empresas disminuyó en septiembre" en los sectores industria, servicios y sobre todo en el comercio, por el descenso en las ventas. El signo positivo ha sido la elevación de la inversión del promedio empresarial.

Resumiendo a modo de pinceladas algunas reflexiones de estos analistas, Roberto Rubio (FUNDE) acepta que existe un problema de demanda en la eco- 
nomía, y sostiene que un poco de keynesianismo (inversión pública) ayudaría a encarrilar la actividad productiva. Hay dos formas de reactivar la producción: a través del gasto del Estado y por medio del crédito. Dos posibles paradojas: en momento de bajo crecimiento se tiene un planteamiento de contención de la demanda pública. Pero, dado que hay un problema estructural para elevar los ingresos, debe activarse la demanda pública. Respecto al crédito, R. Rubio piensa que el problema mayor no son las tasas de interés, sino que la banca no halla dónde colocar tanta liquidez. El nudo a desenmarañar está enmarcado en el crecimiento y la situación fiscal y financiera.

El Ing. Arturo Zablah también ve un posible dinamizante de la actividad productiva en las políticas de inversión pública, que al mismo tiempo que generen empleo, incentiven la demanda. Existen, para ello, fondos provenientes de las privatizaciones; pero lo que falta es la voluntad política. El gobiemo parece no tener un plan y al mismo tiempo el Ejecutivo descarta los serios estudios publicados en el presente año. Todos estos analistas piden al gobiemo que sea transparente y que reconozca que se han encontrado con problemas más graves que los presentados en las estimaciones oficiales. No se ofrecen todas las cifras y sin estos datos no es posible un buen diagnóstico económico, hacer las oportunas propuestas y llegar a un entendimiento nacional. El ejecutivo debe presentar un plan de gobierno que muestre qué es lo que va a hacer; las "alianzas" parecen más bien slogans de campaña... En resumen, algo de neokeynesianismo frente al estancamiento de la demanda global y un programa o plan de acción gubernamental.

Por su parte, los representantes de ASI-ANEP, Cámara de Comercio..., reconocen que prácticamente todos los sectores han decrecido; otra forma de expresar el problema de la demanda nacional deficiente. "El optimismo comienza a declinar". Como representantes del grupo empresarial, se necesita un proceso de búsqueda de un sector que dinamice la economía. Actualmente, afirman, todos los sectores están entrampados y tras la búsqueda de su reactivación. Recomiendan la reactivación del agro, para lo cual ANEP presentará una propuesta de diversificación del sector agrícola. Si el área agropecuaria toma fuerza, todos los demás sectores se verán beneficiados.

La sumatoria de todos estos testimonios e investigaciones aquí citados, y la sumatoria de tantos titulares de nuestros diarios a lo largo de 1999, muestran claramente que nuestra economía está estructuralmente desarticulada. En este sentido, quedan fuera de contexto las afirmaciones visionarias que introducen el programa de la Nueva Alianza. Los analistas económicos piden datos reales y un plan de acción que se inspire en los estudios y propuestas presentados en 1999 por economistas nacionales y extranjeros. Apoyo personalmente esta posición porque, luego de la publicación de Temas claves para un plan de nación, crecimiento con participación (FUSADES) y Estado de la nación en desarrollo humano, resumí en un breve artículo los problemas y lineamientos que estos estu- 
dios ofrecían al nuevo gobiemo para plasmar un Plan de Nación e incluso reconstruir un Ministerio de Planificación". Es realmente preocupante no ver - de momento- una respuesta efectiva de parte del gobiemo. Las aspirinas que ofrece el señor presidente los fines de semana no sirven para mitigar los dolores de cabeza de la economía nacional.

Cuando los representantes de la ASI-ANEP afirman que todos los sectores están deprimidos y entrampados, que el optimismo comienza a declinar y que se necesita un proceso de búsqueda de un sector que dinamice la economía, recordamos los análisis comparativos que hacíamos, hace seis años, de las matrices intersectoriales 1978-1999. Detallábamos los que pudieran ser sectores dinamizantes por sus aportes al valor agregado y como principales oferentes y demandantes de insumos. Decíamos que si el crédito se encauzara hacia estos sectores se fortalecería el efecto multiplicador de la inversión, del empleo y de los ingresos. Yendo un poco hacia atrás, en 1987, utilizando en un estudio econométrico la matriz-1978 (publicada en 1986), llegábamos a concluir que la atención-respuesta a las necesidades básicas de la población podía convertirse en una política de reactivación de la economía. La canasta básica familiar, es decir el mismo mercado nacional tenía la potencialidad (multiplicador $=2,77$ ) de dinamizar a la mayoría de sectores económicos ${ }^{12}$. Estos análisis se hacían con la intención de ayudar al gobiemo: “Aportes económicos de las matrices 1978-1990 a los programas de desarrollo 1994-1999" (Realidad, 39). Otras instituciones, como FUNDE, hicieron similares análisis en esos mismos años.

Pero el gobiemo anterior, con su autoritaria ideología, dictaminó que "En un sistema de economía de mercado no se conciben políticas sectoriales, ya que la mejor política sectorial es una política macroeconómica que fija reglas claras y estables, da libertad a los agentes económicos, facilita la creación de recursos financieros para apoyar la inversión y genera estabilidad y confianza en el cortomediano plazo". Qué fácil es hacer discursos con frases huecas que liberan al Estado del más elemental análisis y dirección de la economía. Con toda razón, la población despidió a ese voluble gobierno con una nota de reprobación, aunque a estos políticos no parece que les impresionan mucho las calificaciones éticas de la población. Hemos perdido una década desatendiendo tantos análisis y propuestas de pasados y presentes institutos de investigación y la historia peligra repetirse con el inactivismo y la ausencia del presente gobierno. Alegra el que haya reclamos por volver al pasado, al análisis sectorial y mejor aún intersectorial, porque esto nos puede llevar a un intento por rearticular lo que nos queda de una economía desmembrada. Por ello, el gobiemo no debería engavetar sino dar mayor publicidad al estudio presentado en enero de 1999 por técnicos del MAG "Revalorización del Sector Agropecuario"'?. Se trata de recuperar el aporte real del sector, parcialmente recogido en las partidas de la contabilidad nacional y reducido a la sola demanda final, resaltando cuantitativamente el valor de los productos sectoriales que entran en las cadenas agroalimentarias como insumos 
o consumos intermedios. La terminología nos dice que se trata de un análisis matricial, reagrupando la matriz 1990 en sólo 13 sectores. Se trata de "probar de manera cuantitativa que el sector agropecuario es efectivamente el verdadero motor del crecimiento económico". Los investigadores del MAG desean "convencer a las autoridades que hacen y toman medidas de política de que el esfuerzo de desarrollo económico nacional debe pasar necesariamente por un acelerado y sostenible crecimiento sectorial". Se trata de probar, de manera cuantitativa, el potencial de reactivación, río-arriba y río-abajo, que el sector agro-pecuario es capaz de transmitir al cuerpo de la economía.

Estos análisis sectoriales ya eran recomendados en el primer documento: Bases para un plan de nación. "El país no puede continuar transitando sin una apuesta estratégica en tomo a su base productiva (No. 35). No podemos apostarle a todo, y como toda opción ello implica dar prioridad a unas cosas y no darla a otras. Definir las áreas prioritarias de desarrollo para nuestro país no es asunto fácil y requiere de una profunda discusión y sólidos compromisos (No. 38). Los criterios fundamentales para la definición de las áreas prioritarias deben ser: los efectos multiplicadores sobre el resto de la economía, las oportunidades de inversión, el logro de equilibrios sectoriales, la integración económica del país y las ventajas competitivas" (No. 39).

Por su parte, el Departamento de Cuentas Macroeconómicas del Banco Central de Reserva (abril de 1999) presenta una actualización de las partidas tradicionales y sistemas de su valorización. Aunque en las páginas 11-12 se describe la estructura de una matriz insumo-producto, lastimosamente no nos of rece una actualización de la malla intersectorial, en forma similar a lo realizado en 1990. En anexo nos of recen sólo dos sábanas del ingreso nacional disponible, a precios corrientes y constantes 1990-1998, tal como aparecen en su revista trimestral. Los cambios en la orientación ideológica y el privilegio acordado a las series macroeconómicas pueden explicar esta laguna. Sin embargo, creemos que el Banco Central cuenta con los técnicos y las técnicas para actualizar, al menos en forma elemental, nuestras matrices insumo-producto, como lo han hecho a nivel subsectorial los técnicos del MAG. Se ha dicho que el Banco Central debe gozar de una independencia activa frente al gobierno de turno. Esta independencia debería ser también académica, de manera que sus buenos y bien formados técnicos pudieran expresar libre y responsablemente sus análisis económicos, su visión de la realidad y sus personales propuestas. Uno de estos oportunos trabajos sería la actualización de nuestras matrices insumo-producto; sólo ellos pueden disponer de los datos requeridos y con esto estarían dando un buen aporte a este proceso de reactivación e integración económica nacional. A partir de estos datos no se verían obligados a maquillar las cifras nacionales, petición que hacen tantos analistas económicos. No deja de ser triste que algunos técnicos del BCR tengan que esperar su jubilación para decir y escribir lo que piensan. 


\section{Arriando las velas}

A modo de recomendación, nuestro análisis de coyuntura 1999 termina diciendo: urge un auténtico proyecto de nación, listando una serie de estudios, antes citados, que nos recomiendan cambiar de timón y de timonel. Esta secuencia de estudios nos vienen a decir explícitamente que el modelo en que se había puesto la confianza ha entrado en verdadera crisis. Han fallado sus cuatro ejes o postulados económicos, al mismo tiempo que sus cinco principios filosóficos eran simples ideales individualistas. Se dijo que la propiedad es condición necesaria para la eficiencia de la producción. Los mismos representantes de las gremiales empresariales aceptan, quizás a regañadientes, que ese no ha sido el resultado. Lo único que ha logrado la gran propiedad es reforzar su concentración, desprivatizando a otros sectores, incluso medianos y más grandes, gestando un latente proceso de irritabilidad. Cada vez son más el número de grupos y personas que critican este proceso de concentración discriminante, donde los oligopolios de propietarios se enfrentan en una guerra a cuchillo. En este sentido, decimos que se trata de una concentración socialmente quebradiza.

Se dijo que el libre mercado asegura la mejor asignación de los recursos y que la competencia garantiza el funcionamiento del mercado. En cierto sentido esto se ha cumplido, pero en contra nuestra. Al carecer de una capacidad competitiva, en razón del rezago tecnológico, el deterioro ambiental y la terciarización económica, ha sido el mercado externo quien ha regido la mejor asignación de los recursos. Las gremiales empresariales piden ahora que se proteja a la industria local. Son cada vez más quienes lamentan la premura y poca transparencia del proceso de privatizaciones, que vino a profundizar la desnacionalización de los activos nacionales. La función subsidiaria del Estado se redujo al subsidio del mercado. La improvisación de políticas sorpresivas (maquila, aranceles, IVA, privatización, dolarización) desconcertaron a las mismas gremiales empresariales. "El Salvador, un país de propietarios" se redujo a pocos propietarios. Mientras tanto, la desarticulación productiva se escondía bajo el toldo de las series macroeconómicas. Como dijera Roberto Rubio (FUNDE): "la política macroeconómica predominante suele hacer de las cifras y estadísticas un fetiche... El desarrollo se ha llegado a convertir en el desarrollo de las series estadísticas, mientras que el bienestar de los pueblos se logra confundir con el bienestar de las variables macroeconómicas"14. La economía está constituida fundamentalmente por su estructura sectorial productiva, y las series macroeconómicas pueden - sólo de momento- ocultar fallas estructurales.

No podemos leer nuestra economía desde una simple secuencia de ciclos de crecimiento mayor y decrecimiento frenado-desaceleración (1992-1995 y 1996-1999), en espera de que, a saber cómo y por qué, se inicie un nuevo ciclo ascendente con la llegada del nuevo milenio. Los calendarios no tienen tal poder milagroso; a lo largo del ciclo económico 1990-1999 se han ido gestando profundos cambios cuan- 
titativos y cualitativos. Con ello, los análisis de coyuntura de corto plazo se convierten en análisis de estructura del mediano-largo plazo. A esa conclusión hemos llegado en el departamento de economía-UCA, y a similar resultado nos llevan los análisis de otros institutos de investigación: la desvertebración de nuestro esqueleto económico. El oligopolio bancario ha tenido parte activa en este proceso.

A modo de botón de muestra trasladamos dos párrafos escritos por nuestro recordado Salvador Osvaldo Bran, en 1997: “Aprovechando la desregulación, el sistema financiero se excedió en el otorgamiento de créditos no productivos, es decir, prestó dinero para la compra de electrodomésticos, mobiliario, vestuario, todo importado; prestó para comprar dólares, adquirir automóviles nuevos y usados, viajes, compras especulativas de bienes raíces, y también para acumulación de inventarios, previo al aumento del impuesto al valor agregado y de las tarifas de servicios públicos. Naturalmente no hubo ahorro por el exceso de consumo que se reflejó en un crecimiento excepcional de las ventas comerciales, aun cuando las tasas de interés eran elevadas. A la par de todo eso, el gobierno no previó estímulos para la producción agrícola e industrial...".

"Un sistema financiero orientado a sus propios fines. Al aprovechar la desregulación, el sistema financiero se ha convertido en el sector más pujante del país, aunque no sea el más eficiente, lo cual puede comprobarse en los estados financieros que semestralmente publican, por ley, las mismas instituciones. Claro que esto no es criticable, al contrario, es la lógica del libre mercado, pero en las actuales circunstancias de desaceleración económica el sistema bancario debería efectuar una revisión de sus fortalezas, oportunidades, debilidades y amenazas, y reflexionar hasta cuándo podrá llegar la "luna de miel" del predominio de las operaciones especulativas sobre las operaciones de apoyo a la producción nacional"'s. Este artículo de S.O. Bran, al finalizar sus treinta largos años de servicio en el Banco Central, ya era una premonición de lo que hoy cosechamos. O. Bran también lamentaba en su artículo la incoherencia de las políticas gubernamentales. La "luna de miel" se ha convertido el elevada mora bancaria. También otros institutos de investigación culpabilizan al sistema bancario por haber contribuido a este proceso de desarticulación económica en el mediano plazo.

Junto con la desvertebración productiva se han ido gestando otros cambios cualitativos. Si se critica la economía de libre mercado, no se la critica en cuanto lugar de intercambio de bienes y servicios, que ya practicaron fenicios y griegos. Lo que hoy se enjuicia a nivel mundial son las motivaciones y las consecuencias que mueven y que generan las "leyes" del mercado. En un mundo, donde incluso por encima de las megaempresas planea la especulación del superimperio financiero y del superimperio de los medios de comunicación social, se gesta un proceso de "destrucción creativa" de ideales y motivaciones que extirpan otros valores tradicionales y morales. Vale la pena trasladar dos testimonios nada sospechosos de crítica visceral. 
El conocido financiero y filántropo G. Soros, que se mueve en las entrañas del mercado financiero, expone así su quinta deficiencia: "Esto me lleva al problema más confuso: el de los valores y la cohesión social. Toda sociedad necesita tener valores compartidos. Los valores del mercado no sirven para este propósito, porque sólo reflejan lo que un participante en el mercado está dispuesto a pagar a otro dentro de un libre intercambio. Los mercados reducen todo, incluidos los seres humanos (mano de obra) y la naturaleza (tierra) a mercancía. Podemos tener una economía de mercado, pero no podemos tener una sociedad de mercado. Además de los mercados, la sociedad necesita tener instituciones que sirvan para fines sociales, como la libertad política y la justicia social. Estas instituciones existen en países concretos, pero no en la sociedad global. El desarollo de una sociedad global se ha quedado retrasado respecto al de una economía global. A menos que se acabe con esta distancia, el sistema capitalista global no sobrevivirá"16...

A. Schelesinger, asesor del ex presidente J. F. Kennedy, analiza los nuevos problemas de la economía de mercado: "El capitalismo ha demostrado ser el motor supremo de la innovación, la producción y la distribución. Pero su método, mientras va dando bandazos hacia adelante, sin atender otra cosa que su propio beneficio, es lo que Joseph Schumpeter llamaba la "destrucción creativa". En su teoría económica, el capitalismo descansa sobre el concepto de equilibrio económico. En la práctica, sus propias virtudes lo arrastran hacia el desequilibrio. Este es el dilema del conservadurismo contemporáneo. El mercado sin restricciones, que adoran los conservadores, mina los valores: estabilidad, moralidad, familia, comunidad, trabajo, disciplina, gratificación demorada, que propugnan los mismos conservadores. El resplandor del mercado, la codicia, el acorto-placismo, la explotación de apetitos lascivos, la facilidad del fraude, la ética del ventajismo, todo ello está en conflicto con las pretendidas ideas conservadoras. Un "capitalismo estacionario" es una contradicción en los términos"17.

Se comprende así que la cumbre mundial sobre el desarrollo social (Copenhague, 1995) haga preceder los análisis sobre el desarrollo de la pobreza y el crecimiento con desempleo con la amplia variedad de refinados delitos gestados por la atomización y la insolidaridad social. Se anticipaba cinco años a lo expresado en el reciente foro de Davos. A este propósito me gusta agregar algunas frases de la entrevista que la revista Idées hiciera, en 1996, al arzobispo de París, Mons. Jean Marie Lustiger. ¿Por qué juzga usted tan severamente a la sociedad liberal? "Abran los ojos y vean el rumbo de nuestra civilización... Da la prioridad a los valores financieros y somete a dichos valores toda la cultura: las costumbres, la vida familiar y las estructuras elementales de la sociedad. El individuo es considerado fundamentalmente como un agente de la vida económica. Toda su formación busca responder a los imperativos de la máquina, producir y ganar... De nuevo zonas enteras de la sociedad se están proletarizando 
y sus hijos queman los supermercados. Una sociedad puede destruirse en pocos años; para reconstruirla harán falta algunas generaciones...

Se ha adoptado la psicología del financista. Si se busca el beneficio inmediato es seguro que se pone en peligro el largo plazo. La valoración financiera sustituye a los proyectos industriales y a flujos destinados a la producción. La gestión financiera de las empresas puede llevar a preferir el beneficio más inmediato o de mayor riesgo sin ponderar otras consecuencias... La moneda es un símbolo abstracto, ella cuantifica toda la realidad. La moneda es una especie de álgebra de la actividad humana, reducida a la medida de la unidad monetaria... La bolsa mundial funciona mejor que Naciones Unidas. Los financieros anticipan la evolución de la humanidad. Pero, ¿es a ellos a quienes corresponde conducirla? Y, ¿a beneficio de quién?

Estos autorizados testimonios, que nos llegan de ambos lados del Atlántico, dibujan en forma realista la dislocación de valores que observamos también en nuestra sociedad. Uno a uno, la mayoría de esos antivalores se vienen imponiendo como normas de conducta, sin mayor remordimiento de conciencia. Nosotros hablamos de las argollas financieras, del corto-placismo, de la inversión especulativa, de las ganancias rápidas e ilícitas, del álgebra de la moneda que reduce toda la actividad humana a la unidad monetaria. También cunde la ética del ventajismo (compadrazgo u otro nombre), la facilidad del fraude, la codicia..., y al mismo tiempo se están proletarizando zonas enteras de nuestra sociedad y, ¿quemarán los supermercados? "Una sociedad puede destruirse en pocos años; para reconstruirla harán falta algunas generaciones". El Dr. Carlos Quintanilla Schmidt, vicepresidente de la República, acaba de decir: "La comupción está en todos los niveles". Es algo muy serio que un vicepresidente afirme que "el aparato estatal está plagado de compción, aunque la solución no es, por completo, responsabilidad del gobiemo, sino de la ciudadanía". Avanzando en la entrevista agrega: "Es que la corrupción está presente en todos los niveles de la vida. Está presente en la sociedad civil, en los mismos medios de comunicación, en las empresas particulares, privadas y estatales, por supuesto. El gran reto del Gobierno es hacer que esos niveles de corrupción disminuyan y se erradiquen"... (El Diario de Hoy, 10 octubre de 1999).

Felicitamos al nuevo gobiemo por su plan de ataque contra la corrupción porque responde, por añadidura, a la recomendación que el Banco Mundial hizo a los gobiemos, en documento fechado el 21 de enero de 1999. "Si establecer un marco efectivo de gobierno es difícil, será imposible si hay corrupción, el factor más corrosivo para el desarrollo, contra el cual debe lucharse sistemáticamente a todo nivel. En particular, debe empezarse por un compromiso enérgico de las autoridades de luchar contra la corrupción a todos los niveles, tanto para evitar que ocurra, como con un sistema para hallar y castigar a los culpables de los actos de corrupción que se comentan. Los niveles más altos deben ponerse a la 
cabeza de los esfuerzos que deben ser constantes y firmes". Felicitamos al actual gobiemo si llega a iniciar y avanzar en este camino del control y castigo de la corrupción, que "también" se multiplicó en los dos anteriores gobiernos.

\section{Un cambio de rumbo}

La Prensa Gräfica, en su sección "El Financiero", se pregunta: “iSe humanizará la globalización? Banco Mundial y FMI se comprometen a reducir la pobreza". Aquí y en anteriores comentarios nos hemos referido al discurso que el Dr. James Wlfensohn, presidente del Banco Mundial, pronunciara en la reunión de Washington, en octubre de 1998, con el título: "La otra crisis". Ahora parece que hasta el mismo FMI da signos de arrepentimiento - tal vez más de atrición que de contrición - al constatar que sus políticas de ajuste estructural han hecho estallar "el clamor de los pobres". Michael Camdessus se expresa como un teólogo de la liberación: "la pobreza que aún existe al final de un siglo de prosperidad es intolerable, y naturalmente el nivel de pobreza reinante es inadmisible. Por tanto, es hora de reaccionar".

En la reunión del pasado septiembre, el Fondo Monetario Intemacional y el Bano Mundial se comprometieron a juntar esfuerzos para construir una nueva arquitectura financiera, un nuevo desarrollo sostenible, fundamentado en las siguientes políticas: "reducir la extrema pobreza, proveer educación primaria universal, igualdad entre los sexos, disminuir las tasas de mortalidad infantil y matema, libre acceso a la salud reproductiva y trabajar a favor del medio ambiente". De acuerdo con José Luis Hernández, redactor de "El Financiero", estas declaraciones de principios ha dado lugar a varias interpretaciones: para muchos analistas esto significa que el modelo está en crisis. Otros piensan que sólo de trata de una revisión de los paradigmas neoliberales (integración del ajuste estructural con el desarrollo social), mientras que algunos banqueros creen que se está gestando un "novo neoliberalismo" de corte humanista.

Otros analistas nacionales agregan sus propios comentarios a este enunciado de principios. Puesto que la mayoría de la población (mundial y nacional) se halla en estado de pobreza y de exclusión, es necesario invertir en desarrollo humano. ¿Se traducirá esto en políticas y en dinero? "Las visiones encontradas entre los que priorizan el desarrollo social frente a los que priorizan el crecimiento tienden a converger más en una nueva síntesis en el debate nacional". Se alude a la corrupción que no ha permitido que los beneficios del crecimiento "rebalsen" a los sectores más vulnerables. "Se necesita flexibilizar la política monetaria y ya no tener esa obsesión por la estabilidad, porque eso retrasa el crecimiento y las posibilidades de empleo". "Los países ricos han aceptado que la globalización ha profundizado las diferencias entre naciones ricas y pobres, con el agravante que esas diferencias se están replicando al interior de los países"1s. 
Algo está cambiando. Se trate de un novo-neoliberalsmo de corte humanitario, o de un reajuste estructural con desarrollo social, o se trate más bien de una crisis sistémica del neo-liberalismo, hasta el FMI nos recomienda un cambio de rumbo. Todo esto tiene algo de sorpresivo. Luis Membreño, columnista habitual de "El Financiero", se pregunta: “¿Será mejor el 2000?”. Su breve perspectiva mundial y nacional es bien objetiva y nos hace aterrizar en la pista deslizante de las "elecciones de marzo". No deja de ser preocupante que, cada dos años, las decisiones económicas s̀e vean supeditadas a las expectativas políticas, más bien partidistas que democráticas. Luis Membeño resume el interrogante. "Si el Gobiemo y los diferentes líderes nacionales logran concertar esfuerzos y acuerdan un plan que permita reorientar nuestra economía para generar un mayor crecimiento económico con equidad, se estarán dando los pasos necesarios para asegurar un mejor futuro para todos los salvadoreños en el año dos mil. De lo contrario, podríamos enfrentamos a otro año perdido, que puede sumir a muchas empresas y familias en una precaria situación económica. Esperamos que sea acogida la primera alternativa y que de esta manera iniciemos el nuevo siglo con un paso firme en la dirección correcta"14.

Estas expectativas se transforman en un serio interrogante. Los líderes partidistas, sobre todo la Asamblea Legislativa, itendrán esta visión realista de la desintegración económica y social con que cerramos el siglo? ¿Votarán de acuerdo a su "conciencia" o tendrán que someterse a determinadas consignas del partido? Puesta la pregunta de otra forma, puesto que en el pasado se aceptaron como lineamientos supremos las políticas emanadas de las instituciones financieras internacion ales, nuestros líderes políticos, ¿se mostrarán lo suficientemente versátiles para hacer suyas las recomendaciones —al menos literales - del FMI y BM para que no se siga profundizando la actual crisis social? "Se han definido los objetivos, se han asumido los compromisos. Ha llegado el momento de actuar. Hagámoslo". Banco Mundial.

\section{Algunas conclusiones}

De todo este conjunto de testimonios y documentos brotan algunas conclusiones, tal vez no unánimemente aceptadas. En primer lugar, que el modelo o mecanismo de funcionamiento en el cual se habían fincado las esperanzas de llegar a ser una sociedad libre, no ha rendido los frutos prometidos. El mercado, por sí sólo, genera grandes problemas de exclusión y discriminación. Lo menos que se puede pedir es que se acepten los hechos, que se analicen las causas y que se presenten nuevas soluciones. Uno de los males mayores ha sido la gestación de una corrupción generalizada e incluso incrementada en la presente década. Este es un fenómeno universalmente reconocido. De acuerdo con las repetidas recomendaciones del Banco Mundial, el gobiemo debería mostrar con hechos concretos que la corrupción es el peor corrosivo del desarrollo social. Al redactar estas líneas, la Corte de Cuentas ha dictaminado que la donación a 
APROAS es ilegal; nos quedamos a la expectativa de la posible sentencia... El vicepresidente de la República dice que se están tomando medidas para combatir la corrupción en el área financiera, en la declaración de impuestos y en la estructura estatal. El erario público se beneficiaría bastante si se comenzara por la evasión-elusión fiscal de los mayores evasores, dado que al finalizar septiembre la recaudación de impuestos es 565 millones inferior a la programada y necesitada.

En un mundo donde se agranda la brecha entre ricos y pobres, las políticas de alivio a la pobreza deben acompañarse con el control de la concentración económica. No se trata de quitar a unos para dar a otros, sino de aplicar políticas redistributivas, directas e indirectas, que transfieran excedentes de unos a inversión productiva y social, que generen empleo y desarrollo social en los otros. Aquiles Montoya aconseja algunas medidas para tal fin, en su análisis de la concentración económica. Si la oferta no ha creado su propia demanda, sin duda el apoyo a la demanda popular puede reactivar la oferta.

La economía tiene un orden y un ordenamiento. Nuestra desintegración productiva obedece al hecho de que, en aras del mercado cortoplacista, hemos transgredido ese orden natural. Releyendo Temas claves para un plan cie nación, Crecimiento con participación y Estado de la nación en desarrollo humano, junto con testimonios más recientes, debemos reiniciar el proceso desde el fortalecimiento y diversificación del sector agrario e industria agropecuaria, siguiendo la secuencia - río-abajo- hacia el sector manufacturero-industrial. Con fecha 13 de octubre la empresa privada (ANEP) recomienda al Ejecutivo medidas complementarias, que dinamicen áreas económicas como la agricultura, la industria y otros sectores que puedan reactivar la economía. Como lo indican los técnicos del MAG, es necesario regresar a los análisis intersectoriales y, para ello, a la actualización de nuestras matrices insumo-producto. No bastan para tal fin los solos Programas Monetarios-Financieros del Banco Central. La Ley Orgánica del Banco Central, en sus considerandos y en su art. $3^{2}$, señala como una de las funciones del Banco Central de Reserva adecuar sus políticas monetaria, cambiaria, crediticia al programa o política de desarrollo del gobierno. Por esta razón es que se solicita del gobierno la emisión de un programa económico nacional.

Conviene tomar en consideración las recomendaciones hechas en la reunión tenida en Costa Rica, en abril de 1999, con el título "Centro América en el siglo XXI", bajo la dirección de los economistas M. Porter y J. Sachs. Allí estuvo presente nuestro presidente y el objetivo era diseñar un Plan Regional. Mejor que cabildear una dolarización por cuanta propia nos interesa, en el mediano-largo plazo, buscar esta integración en las áreas ahí concretadas y que mejorarían los tres sectores económicos de nuestro itsmo. Estos técnicos repetían: "Harvard propone y ustedes los presidentes de estas repúblicas son los promotores. Esta ya no es una opción, es una necesidad. Se acabaron los tiempos en que la región podía basar su economía en el proteccionismo y en la ayuda internacional". En 
el mundo de las grandes trilaterales nos recomiendan la asociación regional. Por su parte, M. Porter nos decía que ya no bastan las ventajas comparativas, sino las ventajas competitivas, que descansan en factores mucho más complejos, como la fuerza laboral educada, una infraestructura sofisticada, inversiones constantes y una innovación en tecnología y procesos ${ }^{21}$. También nuestros próximos socios comerciales necesitan esta integración.

Es una medida positiva la reciente promesa del gobiemo de crear un fondo que financiará las necesidades de la microempresa, a través de un banco de segundo piso, similar al BMI. La microempresa está pasando a ser un foco de atención de instituciones públicas y privadas, por su importancia en la generación de empleo, ingresos, participación en el PIB, y con ello un factor de reactivación del mercado intemo. Es necesario combinar políticas que vengan a fortalecer tanto el mercado interno como el mercado extemo, mutuamente interrelacionados para impulsar la demanda global. Puesto que también otras instituciones privadas y organismos no gubemamentales se están dedicando al estudio de los problemas y soluciones a favor de la microempresa, ojalá se pudiera integrar una colaboración conjunta del gobiemo y estas instituciones, dada la importancia de este sector.

En un contexto de alivio a la expandida pobreza, se impone - por razones morales y económicas - la implantación de una economía de sobriedad o de austeridad, donde se controlen, se graven fuertemente y se desanimen importaciones públicas y privadas que resultan costosas e irritantes en nuestro escenario nacional. No tiene el menor sentido la importación de armas y de casinos o casas de juego que vienen a fomentar más bien actividades ilícitas; y pueden agregarse otra lista de bienes superfluos, que por lo menos deberían pagar elevados impuestos. Esta norma de austeridad debería tomarse en cuenta en la preparación del Presupuesto-2000 y en los informes que presentan los ministros ante la Asamblea Legislativa sobre la realización de sus respectivos presupuestos. Creo que bastantes personas se preguntan si, dadas las estrecheces de los presupuestos estatales, es adecuado seguir aprobando unos 950 millones de colones al Ramo de Defensa Nacional, cuando ya se dedican 1468 millones al Ramo de Seguridad Pública. ¿No ha llegado el tiempo de reducir la primera partida a la mitad o tercera parte, sin que por ello mengüe su "productividad". De acuerdo con las nuevas normativas del FMI y BM, el gobierno debería mostrarse firme en la aplicación de estas medidas de austeridad.

Hay otros desafíos que transcienden el radar de un programa económico. Se trata de la pérdida de valores tradicionales y morales, reflejados en los testimonios de Soros, Schelesinger, Lustiger..., que también carcomen la solidaridad social. Sin duda esta tarea es más nacional, más de todos, a comenzar por las familias, las instituciones de educación, las religiones, los medios de comunicación social... y el Estado, que debe ser un "creador de valores". En esta función 
moralizadora, un modelo de austeridad, un modelo que busque el crecimiento con equidad y con participación, algo pudiera ir haciendo en el mediano plazo. Si hasta el FMI parece dar muestras de arrepentimiento y de cambio de agujas, nosotros no debemos perder las esperanzas.

Con el documento Bases para un plan de nación se generaron no sólo respuestas con contenidos realistas, sino también nació un espíritu de participación y colaboración con las autoridades públicas. Se abrió un cauce y un deseo de diálogo para buscar juntos soluciones nacionales. El Gobierno debe, por su parte, completar su propio lema de "responsabilidad compartida", continuando este proceso de diálogo y consulta. Quienes en los años cincuenta y sesenta hacíamos nuestros estudios en Europa occidental (Bélgica, Francia...) oímos y aprendimos algo de ese modelo que llamaban "planificación democrática, planificación indicativa, economía concertada" y, por qué no decirlo, "planificación por la salida" (Jean Monet). Reunirse, dialogar, proponer problemas y dar soluciones alternativas. Ese es un modelo de economía concertada y democrática. Si entramos en esta nueva fase, "algo está cambiando".

\section{Notas}

1. L. A. González, "Estado, sociedad y economía en El Salvador: 1980-1999", ECA, 1999; p. 594.

2. Ibidem, p. 595.

3. Ibidem, pp. 597 y 598.

4. F. J. Ibisate, "Cumbre mundial sobre el desarrollo social, 1995: la pobreza, el desempleo y la integración social", Realidad, 42, 1994, pp. 841-870.

5. F.J. Ibisate, "En búsqueda de una tercera vía", $E C A, 1998$, pp. 464-470.

6. J. Wolfensohn, "La otra crisis", ECA, 1998, pp. 1003-1009.

7. A. Montoya, "La concentración de la actividad económica en El Salvador", ECA, 1999, pp. 429-457.

8. M. Sevilla, "Visión global sobre la concentración económica en El Salvador", Boletín de Ciencias Económicas y Sociales, mayo-junio, 1984, pp. 155-190.

9. Departamento de Economía, “Análisis de coyuntura económica”, ECA, 611-612, 1999.

10. F.J. Ibisate “¿Es el crecimiento la locomotora de nuestra economía?”, ECA, 1997, pp. 799- 817.

11. F.J. Ibisate, "Estado y plan de nación", Realidad, 70, 1999.

12. J. Alfaro y A.M. Orellana, "Necesidades básicas y reactivación económica", Tesis de graduación, Dpto. de Economía-UCA, julio, 1987.

13. MAG, Politica agrícola: Revalorización del sector agropecuario, Vol. II, 1, enero, 1999.

14. F.R. Rubio, "Los desafíos de la sociedad salvadoreña de cara al tercer milenio", FUNDE, Alternativas para el desarrollo, 57, enero-febrero, 1997, p. 4.

15. S.O. Bran, “1997: ¡cambio de rumbo económico?”, ECA, 1997, pp. 537 y 542.

16. G. Soros, "Hacia una sociedad abierta global", El País, 23 de diciembre de 1997.

17. A. Schelesinger, “ ¿Tiene futuro la democracia?”, Revista de Politica Exterior, noviembre- diciembre, 1997, pp. 135-136. 
18. J.L. Henríques, “¿Se humanizará la globalización?”, La Prensa Gráfica, El Financiero, 12 de octubre de 1999, p. 16-B.

19. L. Membreño, “¿Será mejor el 2000?”, La Prensa Gráfica. El Financiero, 12 de octubre de 1999, p. 4B.

20. INCAE, "Centroamérica en el siglo XXI: una agenda para la competitividad y el desarrollo sostenible", San José, Costa Rica, abril, 1999. 